Article

\title{
Sensibility Analysis of the Hydraulic Conductivity Anisotropy on Seepage and Stability of Sandy and Clayey Slope
}

\author{
Shuyang Yu ${ }^{1} \mathbb{D}$, Xuhua Ren ${ }^{1,2, *}$, Jixun Zhang ${ }^{1}$, Haijun Wang ${ }^{3}$ and Zhitao Zhang ${ }^{3}$ \\ 1 College of Water Conservancy and Hydro-Power Engineering, Hohai University, Nanjing 210098, China; \\ yushuyang_hhu@163.com (S.Y.); zhangjixun@hhu.edu.cn (J.Z.) \\ 2 Collaborative Innovation Center on Water Safety and Water Science, Hohai University, \\ Nanjing 210098, China \\ 3 State Key Laboratory of Hydrology-Water Resource and Hydraulic Engineering, Nanjing Hydraulic Research \\ Institute, Nanjing 210029, China; wanghaijun@163.com (H.W.); zhangzhitao1234@sina.com.cn (Z.Z.) \\ * Correspondence: renxh@hhu.edu.cn; Tel.: +86-133-0518-1963
}

Received: 1 December 2019; Accepted: 16 January 2020; Published: 18 January 2020

\begin{abstract}
Evaluation of slope stability under rainfall is an important topic of Geotechnical Engineering. In order to study the influence of anisotropy ratio $\left(k_{r}=k_{x} / k_{y}\right)$ and anisotropy direction $(\alpha)$ on the seepage and stability of a slope, the SEEP/W and SLOPE/W modules in Geo-studio were utilized to carry out the numerical analysis of a homogeneous slope in Luogang District, Guangzhou City, China, which is based on the theory of unsaturated seepage and stability. Two kinds of soils (clay and sand) were included. Results show that: For sandy soil slope, the increase of $k_{r}$ promotes the rainfall infiltration, and the decrease of $\alpha$ prevents the rainfall infiltration. The maximum water content of the surface (MWCS) reaches maximum with the increase of $k_{r}$ and $\alpha$. The rising height of groundwater (RHG) is $-3-4 \mathrm{~m}$ and the safety factor (SF) is 1.3-1.7. For clayey soil slope, variations of $k_{r}$ and $\alpha$ have little impact on the seepage characteristics and slope stability. The MWCS remains almost the same. The rainfall infiltration depth (RID) is $0.5-1 \mathrm{~m}$ and the SF is about 1.7. Therefore, for sandy soil slope, it is not only necessary to consider the influence of $k_{r}$, but also the influence of $\alpha$. For clayey soil slope, it can be treated as isotropic material to simplify calculation.
\end{abstract}

Keywords: hydraulic conductivity anisotropy; sandy soil slope; clayey soil slope; seepage characteristics; slope stability; numerical simulation

\section{Introduction}

Slope stability is an important engineering problem in the geotechnical field, for example, the slope stability of the excavation of a foundation pit [1], the regulation of a riparian slope [2], and the stability of a high slope under complex geological environment in a reservoir area [3], etc. Slope failures mainly include external and internal causes. The external causes include rainfall [4-6], reservoir water level fluctuations [7-9], earthquakes [10-12], human activities such as excavation or blasting [1,3-15], etc. The internal causes are mainly affected by the properties of the slope soil, which include soil types [16-18], unsaturated characteristics [19-21], soil strength [22-24], etc. Rainfall is the key factor triggering the landslide, which accounts for $51 \%$ of all the landslide disasters, according to some relevant investigations [25]. Rainfall usually occurs in rainy seasons, which is concentrated and has a long duration and leads to landslide easily. The main reasons for slope instability caused by rainfall are as follows: (1) Rainfall increases the groundwater level inside the slope, which reduces the effective stress and shear strength of the soil. (2) Rainfall increases the slide force of the slope, which aggravates the slope instability. The main consequence for slope instability caused by rainfall is reflected in these 
two aspects: (1) Landslide causes damage to buildings in the area where the slope is located. (2) Landslide threatens the lives and properties of the residents around the disaster area. For example, on 16 September 2011, heavy rainfall (250 mm/day, cumulative $430 \mathrm{~mm}$ ) in Nanjiang County, Sichuan Province, China, induced thousands of landslides, and on 29 April 2015, the groundwater level in Dangchuan, Heifangtai, Gansu Province, China, rose due to heavy rainfall, which caused a large-scale slope failure [26]. Therefore, it is important to grasp the law and influencing factors of slope instability caused by rainfall in order to correctly understand the mechanism of rainfall infiltration and to prevent and control landslide disasters.

Scholars have conducted large numbers of research studies on the rainfall infiltration mechanism. The research results mainly focused on theory, experiments, and numerical simulations. With respect to theoretical research, Green-Ampt Semi-Analytical Method [27] was the first method to describe the transient infiltration process of rain water in unsaturated soils. It is assumed that the wetting front moves down along the depth direction and the velocity remains unchanged. The volume of water content of the soil after the wetting front is $\theta_{0}$ (completely saturated), and the initial water content of the soil before the front is $\theta_{i}$. The rainfall intensity is always higher than the infiltration capacity of the soil, and the actual infiltration rate is equal to the infiltration capacity of the soil. Mein et al. [28] improved the Green-Ampt model and rainfall infiltration process was divided into two periods. The first stage is the free infiltration period, and the rainfall intensity in this stage is less than the soil infiltration capacity. The second stage is the ponding infiltration period, and the rainfall intensity is greater than the soil infiltration capacity. Chu et al. [29] divided the non-uniform rainfall process into several uniform periods, and calculated the infiltration process according to whether there will be ponding. Chen et al. [30] derived a uniform slope rainfall infiltration model based on the Green-Ampt model. For experimental research, Wu et al. [31] carried out the laboratory model test of landslide under artificial rainfall, and the influence of rain water infiltration on the slope failure was analyzed. Li et al. [32] studied the influence of rainfall on the internal mechanical response characteristics of slope based on fiber grating monitoring technology. Zhang et al. [33] systematically investigated the stability of Xiakou slope under rainfall based on the field monitoring data. In the aspect of numerical simulation, Hao et al. [34] simulated the variations of stability of a typical slope under rainfall based on the limit equilibrium method. Wang et al. [35] used XFEM (extended finite element method) to simulate the crack propagation process in a slope under heavy rain. Dou et al. [36] considered the spatial variability of hydraulic conductivity of slope soil based on the Monte Carlo method, and simulated the seepage characteristics and slope stability. However, most of the previous studies regarded the slope materials as isotropic materials. According to the SEM (scanning electron microscope) microcosmic study of Song et al. [37], the anisotropy of permeability coefficient is caused by the flocculation microstructure of clay and other soils, meanwhile, soil permeability coefficient anisotropy is greatly affected by dry density and freeze-thaw cycles [38]. Generally speaking, the hydraulic conductivity anisotropy ratio $\left(k_{\mathrm{x}} / k_{\mathrm{y}}\right)$ can reach $2-10$, and it is possible to reach 100 for clayey soil [39]. There exist joint cracks in rock slope $[40,41]$, which lead to strong anisotropy of seepage characteristics. The coefficient anisotropy not only has great influences on the transient seepage but also has an impact on the safety factor of the slope. According to Mahmood et al. [42], the difference of slope safety factors between considering and not considering soil anisotropy will be about 40\% [43]. But most of the previous studies ignored the seepage anisotropy of slope soil, and the research results of soil anisotropy of slope were few and incomplete. Yeh et al. [44] took into account the hydraulic conductivity anisotropy ratio of soil slope, and simulated the seepage characteristics and local safety factors, but ignored the hydraulic conductivity anisotropy direction. In fact, the horizontal permeability coefficient $k_{x}$ and vertical permeability coefficient $k_{y}$ coincide with the natural coordinate axis only in some special cases such as layered crushed earth dam or naturally deposited layered soil. In nature, there are more cases where the anisotropy principal direction does not coincide with the coordinate axis. The actual conditions cannot be accurately reflected only by considering the hydraulic conductivity anisotropy ratio. 
In view of the shortcomings of previous studies, the mathematical definition of hydraulic conductivity anisotropy ratio and direction are firstly described in this paper. The SEEP/W and SLOPE/W modules in Geo-studio were utilized to carry out the numerical analysis of a homogeneous slope in Luogang District, Guangzhou City, China [45]. Geo-studio is a professional software suitable for analyzing the seepage and stability of soil slopes, and the numerical results were consistent with the experimental results and field investigations. For example, Jiang et al. [46] analyzed the seepage and stability of a cracked slope with SEEP/W and SLOPE/W. Duong T.T. [2] used the Geo-studio program to study the effects of soil hydraulic conductivity and rainfall intensity on riverbank stability. Muqdad Al-Juboori et al. [47-49] conducted the machine learning research based on SEEP/W. Therefore, this software was utilized in this paper to analyze the effect of hydraulic conductivity anisotropy. Two kinds of soil (clay and sand) and the hydraulic conductivity anisotropy ratio and direction were included. Then the volume water content, rainfall infiltration depth (RID), rising height of groundwater (RHG) and maximum water content of the surface (MWCS) of three typical sections of slope (top, middle, and toe) were analyzed in detail. Finally, the safety factors (SF) of the slope under different conditions were evaluated. The research results provide some references for the understanding of the seepage anisotropy law and prevention of landslides.

\section{Methods and Theory}

\subsection{Theory of Unsaturated Seepage}

The SEEP/W module in Geo-studio was utilized to simulate the rainfall infiltration, and the seepage control equation in the SEEP/W was derived from the saturated and unsaturated Darcy's law [50], which can be expressed as

$$
\frac{\partial}{\partial x}\left(k_{x} \frac{\partial H}{\partial x}\right)+\frac{\partial}{\partial y}\left(k_{y} \frac{\partial H}{\partial y}\right)+Q=m_{w} \gamma_{w} \frac{\partial H}{\partial t} .
$$

In Equation (1), $x$ and $y$ are the coordinates in the direction of $x$ and $y, k_{x}$ is the hydraulic conductivity in the $x$ direction, $k_{y}$ is the hydraulic conductivity in the y direction, $H$ is the total head, $Q$ is the applied boundary flux, $t$ is the time, $m_{w}$ is the slope of the storage curve, and $\gamma_{w}$ is the unit weight of water.

Applying the Galerkin method of weighed residual to the governing differential equation, the finite element for two-dimensional seepage equation can be derived as

$$
\tau \int_{A}\left([B]^{T}[C][B]\right) d A\{H\}+\tau \int_{A}(\lambda\langle N\rangle\langle N\rangle) d A\{H\}, t=q \tau \int_{L}\left(\langle N\rangle^{T}\right) d L .
$$

In Equation (2), $[B]$ is the gradient matrix, $[C]$ is the element hydraulic conductivity matrix, $[H]$ is the vector of nodal heads, $\langle N>$ is the vector of interpolating function, $q$ is the unit flux across the edge of an element, $\tau$ is the thickness of an element, $\lambda$ is the storage term for a transient seepage equal to $m_{w} \gamma_{w}, \mathrm{~A}$ is a designation for summation over the area of an element, and $L$ is a designation for summation over the edge of an element.

In an abbreviated form, the finite element seepage equation can be expressed as

$$
[K]\{H\}+[M]\{H\}, t=\{Q\} .
$$

In Equation (3), $[K]$ is the element characteristic matrix, $[M]$ is the element mass matrix, and $\{Q\}$ is the element applied flux vector. 


\subsection{Effect of Negative Pore-Water Pressures}

In locations above the groundwater table, the pore-water pressure in the soil is negative relative to the pore-air pressure. This negative pore-water pressure is commonly referred to as the matric suction of the soil. Under negative pore-water pressure conditions the shear strength may not change at the same rate as for total and positive pore-water pressure changes. Therefore, a modified form of the Mohr-Coulomb equation must be used to describe the shear strength of an unsaturated soil (i.e., the soil with negative pore-water pressures). The shear strength equation is [51]

$$
s=c^{\prime}+\sigma_{n} \tan \varphi^{\prime}+\left(u_{a}-u_{w}\right) \tan \varphi_{b} .
$$

In Equation (4), $s$ is the unsaturated shear strength, $c^{\prime}$ is the cohesive strength, $\varphi^{\prime}$ is the frictional strength, $\varphi_{b}$ is an angle defining the increase in shear strength for an increase in suction, $u_{\mathrm{a}}$ is the pore-air pressure, and $u_{\mathrm{w}}$ is the pore-water pressure.

\subsection{Safety Factor for Unsaturated Soil}

SLOPE/W adopts the Morgenstern-Price method based on limit equilibrium theory to calculate the safety factor. The modified method strictly satisfies the force balance and torque balance, and the calculation accuracy is high. The expression is listed below:

$$
F_{\mathrm{S}}=\frac{\sum_{i=1}^{n_{\mathrm{S}}} \frac{c^{\prime} b_{i}+\left(W_{\mathrm{i}}+P_{i} \cos \beta_{\mathrm{i}}-u_{a} b_{i}\right) \tan \varphi_{\mathrm{i}}^{\prime}+\left(u_{\mathrm{a}}-u_{\mathrm{w}}\right) b_{\mathrm{i}} \tan \varphi_{\mathrm{b}}}{\left[1+\left(\tan \varphi_{\mathrm{i}}^{\prime} \tan \alpha_{\mathrm{i}}\right) / F_{\mathrm{s}}\right] \cos \alpha_{\mathrm{i}}}}{\sum_{\mathrm{i}=1}^{\mathrm{n}_{\mathrm{s}}} W_{\mathrm{i}} \sin \alpha_{i}-r_{i} P_{i}} .
$$

In Equation (5), $c_{i}{ }^{\prime}$ is the cohesive strength for every soil slice, $i$ is the soil slice number, $W_{i}$ is the weight of every soil slice, $P_{i}$ is the water pressure, $\beta_{i}$ is the angle of the bottom of the soil slice, $b_{i}$ is the length of every soil slice, $\varphi_{i}{ }^{\prime}$ is the frictional strength for every soil slice, $r_{i}$ is the radius of the sliding arc, and $F_{\mathrm{S}}$ is the safety factor.

\section{Numerical Model Framework}

\subsection{Numerical Model and Boundary Conditions}

The case study is a homogeneous slope in Luogang District, Guangzhou City, China [46]. The slope height is $16 \mathrm{~m}$, which is divided into 2 grades with a width of $2 \mathrm{~m}$. In order to reduce the influence of boundary conditions, the range was extended and the model was divided into 13,484 nodes and 13,279 units, which are shown in Figure 1.

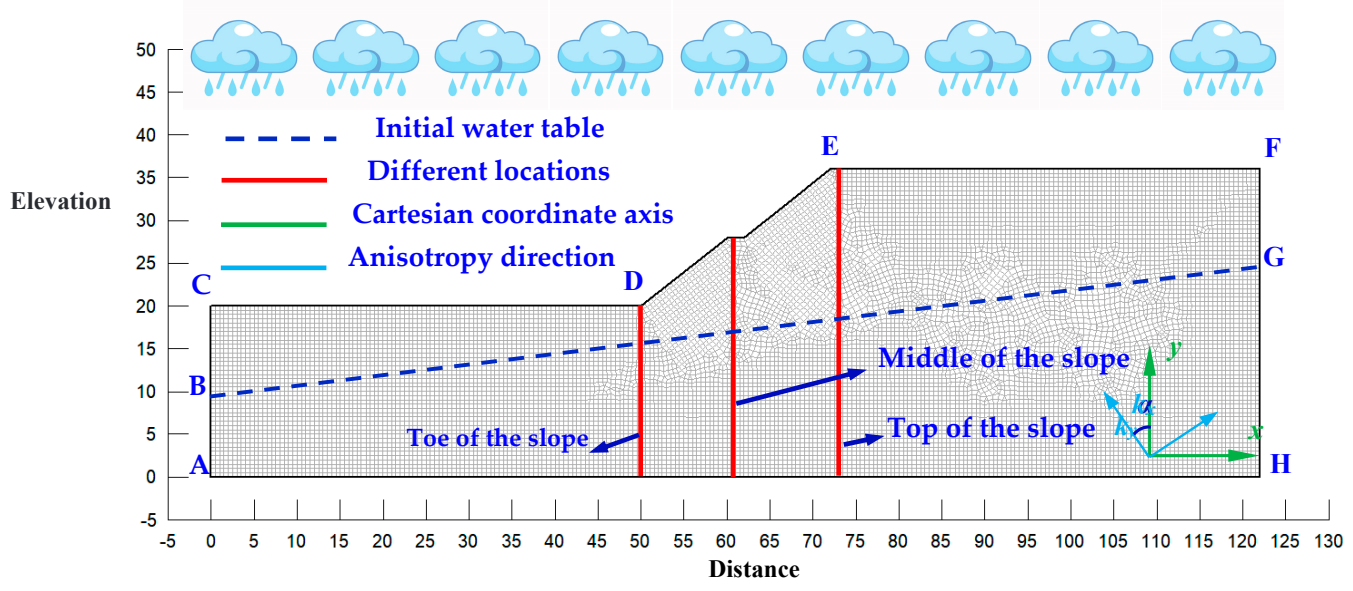

Figure 1. Illustration of slope model. 
To investigate the seepage characteristics at different positions, three sections were set to reflect the effect of hydraulic conductivity anisotropy, whose positions were $x=73 \mathrm{~m}$ (top of the slope), $x=61 \mathrm{~m}$ (middle of the slope), and $x=50 \mathrm{~m}$ (toe of the slope). The boundary conditions were as follows: AB and GH were the fixed water level boundaries of $9 \mathrm{~m}$ and $24 \mathrm{~m}$, respectively. CDEF was the rainfall infiltration boundary. BC and GF were small flux boundaries. AH was the impervious boundary.

\subsection{Unsaturated Soil Properties}

The soil-water characteristic curves (SWCC) adopted the Fredlund and Xing model, which can be written as [52]

$$
k_{w}=k_{s} \frac{\sum_{i=j}^{N} \frac{\Theta\left(e^{y}\right)-\Theta(\Psi)}{e^{y_{i}}} \Theta^{\prime}\left(e^{y_{i}}\right)}{\sum_{i=1}^{N} \frac{\Theta\left(e^{y}\right)-\Theta_{s}}{e^{y_{i}}} \Theta^{\prime}\left(e^{y_{i}}\right)} .
$$

In Equation (6), $k_{w}$ is the calculated conductivity for a specified water content or negative pore-water pressure, $k_{s}$ is the measured saturated conductivity, $\Theta_{s}$ is the volumetric water content, e is the natural number 2.71828, $y$ is a dummy variable of integration representing the logarithm of negative pore-water pressure, $i$ is the interval between the range of $j$ to $N, j$ is the least negative pore-water pressure to be described by the final function, $N$ is the maximum negative pore-water pressure to be described by the final function, $\Psi$ is the suction corresponding to the jth interval, $\Theta^{\prime}$ is the first derivative of the equation, and $\Theta$ can be described as

$$
\Theta=C(\Psi) \frac{\Theta_{S}}{\left\{\ln \left[\mathrm{e}+\left(\frac{\Psi}{a}\right)^{n}\right]\right\}^{m}} .
$$

In Equation (7), a is the air-entry value of the soil, $n$ is a parameter that controls the slope at the inflection point in the volumetric water content function, $m$ is a parameter that is related to the retention capacity, and $C(\Psi)$ is a correcting function defined as

$$
C(\Psi)=1-\frac{\ln \left(1+\frac{\Psi}{C_{r}}\right)}{\ln \left(1+\frac{1000000}{C_{r}}\right)} .
$$

In Equation (8), $C_{r}$ is a constant related to the matric suction corresponding to the retention capacity.

The sandy soil and clayey soil were selected for analysis, which represent the high and low permeability [53], as shown in Figure 2. The unsaturated parameter values are shown in Table 1 [54], and the SWCC curves are shown in Figure 3.
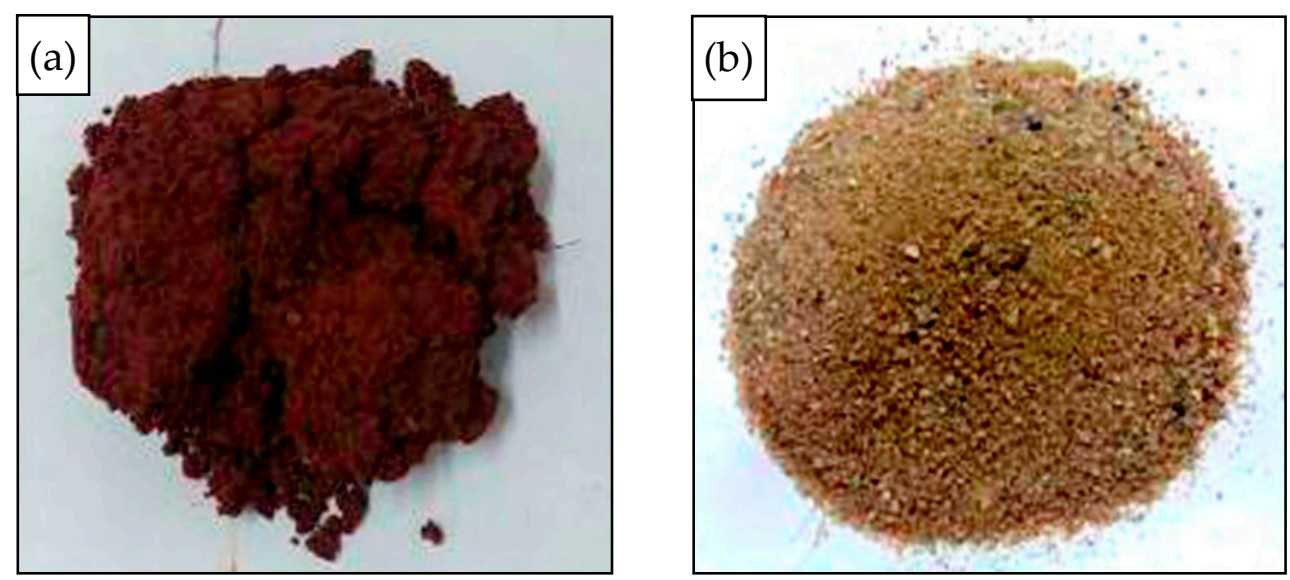

Figure 2. Typical appearance of sandy and clayey soil. (a) Clayey soil. (b) Sandy soil. 
Table 1. Unsaturated parameter values.

\begin{tabular}{ccccccc}
\hline \multirow{2}{*}{ Soil Type } & \multicolumn{4}{c}{ SWCC Parameters } & \multicolumn{3}{c}{ Permeability Coefficient } \\
\cline { 2 - 7 } & $\boldsymbol{a} / \mathbf{k P a}$ & $\boldsymbol{m}$ & $\boldsymbol{n}$ & $\boldsymbol{\theta} / \%$ & $\boldsymbol{k}_{\mathbf{x}} /(\mathbf{m} / \mathbf{s})$ & $\boldsymbol{k}_{\mathbf{x}} /(\mathbf{m} / \mathrm{day})$ \\
\hline Sand & 10 & 1 & 1 & 45 & $10^{-4}$ & 8.64 \\
Clay & 100 & 1 & 1 & 45 & $10^{-6}$ & 0.0864 \\
\hline
\end{tabular}

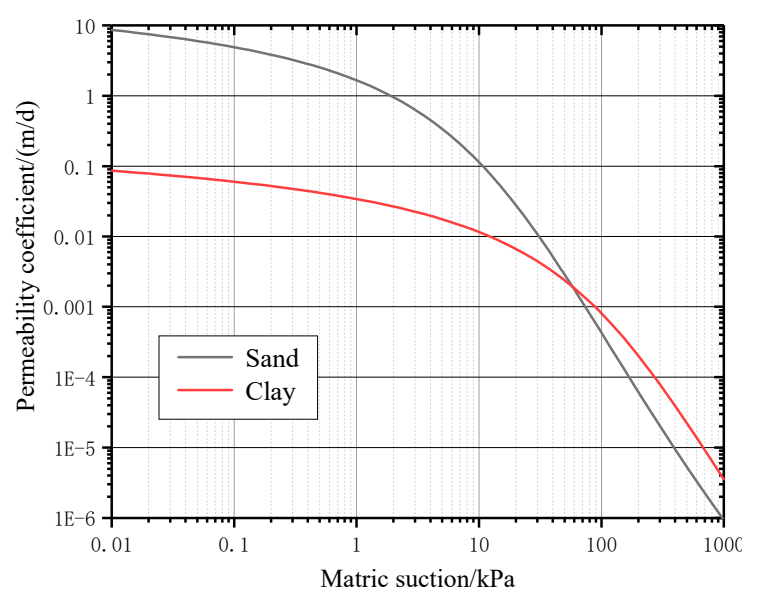

(a)

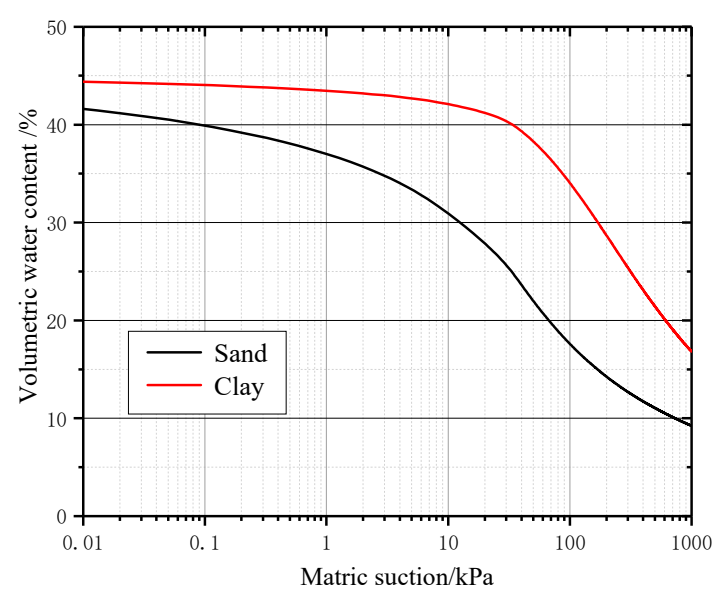

(b)

Figure 3. SWCC curves. (a) Permeability coefficient function. (b) Volume water content function.

\subsection{Definition of Anisotropy and Calculation Conditions}

Previous studies mostly ignored the anisotropy ratio and direction. In fact, anisotropy widely exists in the soil. For the hydraulic conductivity matrix [C] in Equation (2), it can be expressed as

$$
[C]=\left[\begin{array}{ll}
C_{11} & C_{12} \\
C_{21} & C_{22}
\end{array}\right]
$$

In Equation (9), $C_{11}=k_{x} \cos ^{2} \alpha+k_{y} \sin ^{2} \alpha, C_{22}=k_{x} \sin ^{2} \alpha+k_{y} \cos ^{2} \alpha$, and $C_{12}=C_{21}=k_{x} \sin \alpha \cos \alpha+$ $k_{y} \sin \alpha \cos \alpha$. The $k_{x}, k_{y}$, the anisotropy direction $\alpha$ can be defined according to Figure 2 . The $k_{x}$ is the horizontal permeability coefficient, $k_{y}$ is the vertical permeability coefficient, and $\alpha$ is the direction between $k_{y}$ and $y$ axis. When $\alpha=0^{\circ},[C]$ is reduced to

$$
[C]=\left[\begin{array}{cc}
k_{\mathrm{x}} & 0 \\
0 & k_{y}
\end{array}\right]
$$

Equation (10) was adopted in [44], with only considering the anisotropy ratio $k_{r}=k_{x} / k_{y}$. However, the definition of anisotropy not only includes the ratio $k_{r}$ but also the direction $\alpha$. Previous investigations ignored the anisotropy, especially the anisotropy direction $\alpha$.

To completely discuss the anisotropy of sandy soil and clayey soil, including the anisotropy ratio $k_{r}$ and the anisotropy direction $\alpha$, the calculation conditions are shown in Table 2, which includes the anisotropy ratio $k_{r}=1,10,50,100$, and the anisotropy direction $\alpha=0^{\circ}, 15^{\circ}, 30^{\circ}, 45^{\circ}, 60^{\circ}, 75^{\circ}$, and $90^{\circ}$. The range of $k_{r}$ and $\alpha$ were selected according to Gilbert el al. [39]. To reflect the influence of the heavy rainfall, the rainfall intensity is set to $10^{-6} \mathrm{~m} / \mathrm{s}$, and the rainfall duration time is set to $120 \mathrm{~h}$. Meanwhile, $120 \mathrm{~h}$ of rainfall stop was also considered. 
Table 2. Different calculation conditions.

\begin{tabular}{|c|c|c|c|c|}
\hline Rainfall Intensity (m/s) & Soil Type & $k_{x}(\mathrm{~m} / \mathrm{s})$ & $k_{r}$ & $\alpha /^{\circ}$ \\
\hline \multirow[t]{2}{*}{$10^{-6}$} & Sand & $10^{-4}$ & $\begin{array}{c}1 \\
10 \\
50 \\
100\end{array}$ & $\begin{array}{c}0 \\
15 \\
30 \\
45 \\
60 \\
75 \\
90\end{array}$ \\
\hline & Clay & $10^{-6}$ & $\begin{array}{c}1 \\
10 \\
50 \\
100\end{array}$ & $\begin{array}{c}0 \\
15 \\
30 \\
45 \\
60 \\
75 \\
90\end{array}$ \\
\hline
\end{tabular}

\section{Results and Discussions}

\subsection{Initial Conditions}

Initial conditions are important for further numerical simulations. In order to determine the initial conditions more accurately in this paper, the maximum negative pore water pressure of $-25 \mathrm{kPa}$, $-50 \mathrm{kPa}$, and $-75 \mathrm{kPa}$ and the specified annual average rainfall infiltration were numerically simulated, and the pore pressure variation of sandy soil and clayey soil are shown in Figure 4. Under the annual average rainfall infiltration, the initial pore pressure of sand and clay was obviously different in that the initial pore pressure of sandy soil slope was slightly larger than clayey soil slope, but the distribution along the elevation was similar, which was reflected in that the initial pore water pressure firstly remained unchanged then gradually increased along the elevation. The maximum negative pore-water pressure was close to $-50 \mathrm{kPa}$, which was selected as the initial condition of all the calculation conditions in this paper.

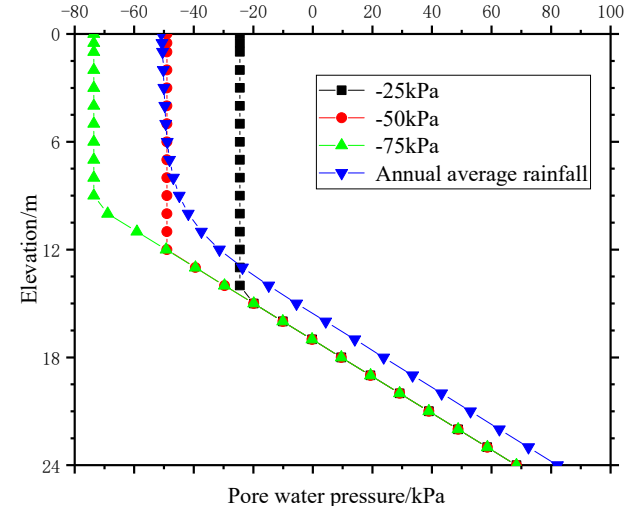

(a)

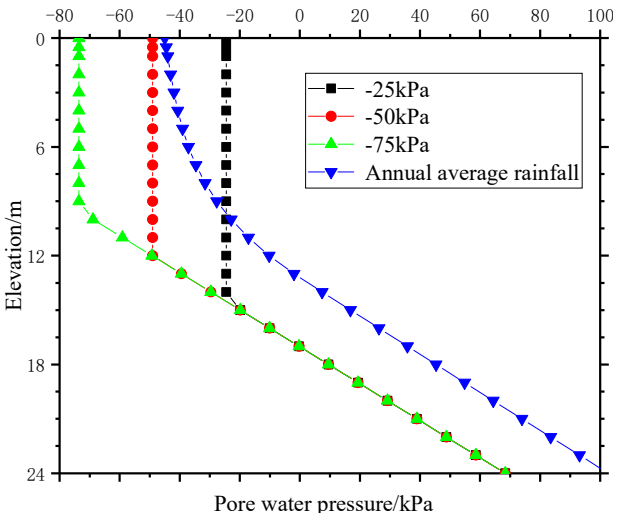

(b)

Figure 4. Initial pore pressure distribution. (a) Sandy soil. (b) Clayey soil.

\subsection{Variation of Volumetric Water Content}

According to the calculation conditions in Table 2, we carried out a total number of 54 numerical simulations, and obtained, in all, 162 sections of volumetric water content variation. For ease of reading, this section will carry out the discussion based on the classification of sandy soil and clayey soil slope. The variations of volumetric water content of different $\alpha$ values with $k_{r}=10$ and $k_{r}=100$ are shown in Figures 5 and 6 to illustrate the influence of anisotropy direction $\alpha$ on seepage characteristics, and different $k_{r}$ values with $\alpha=0^{\circ}, 45^{\circ}$, and $90^{\circ}$ are also displayed in Figures 7 and 8 to show the impact of anisotropy ratio $k_{r}$. The volumetric water content of the 120th $\mathrm{h}$ is only shown in Figures 5-8. 


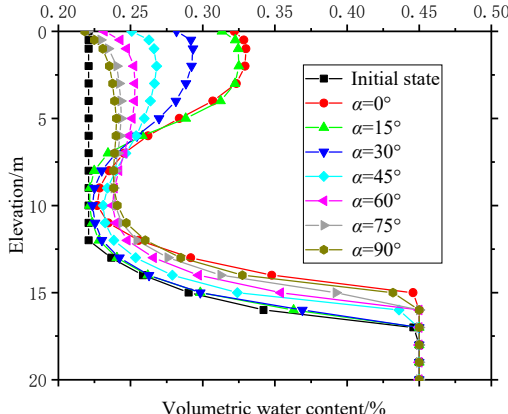

(a)

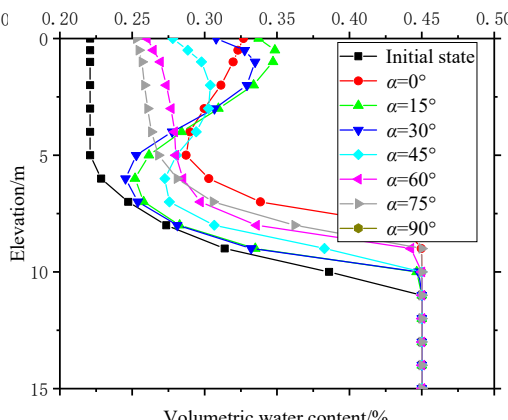

(b)

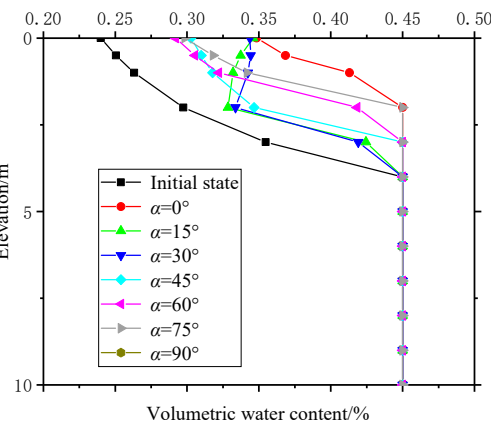

(c)

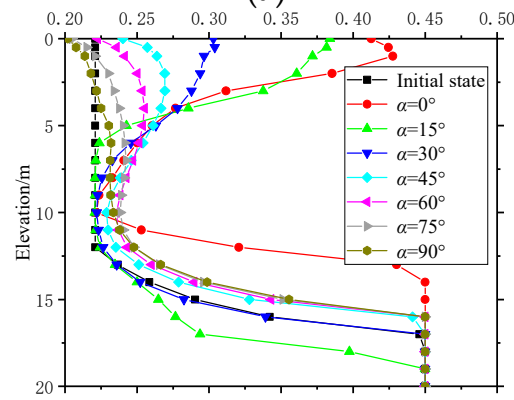

Volumetric water content $\%$

(d)

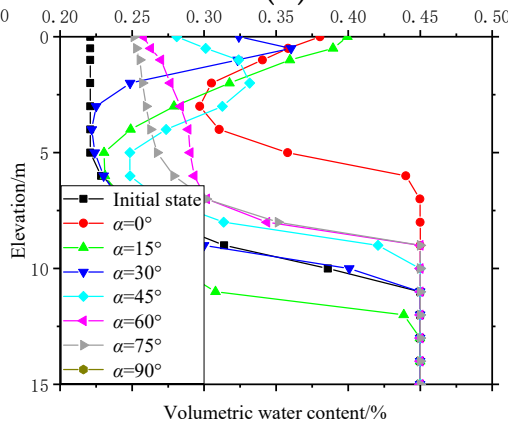

(e)

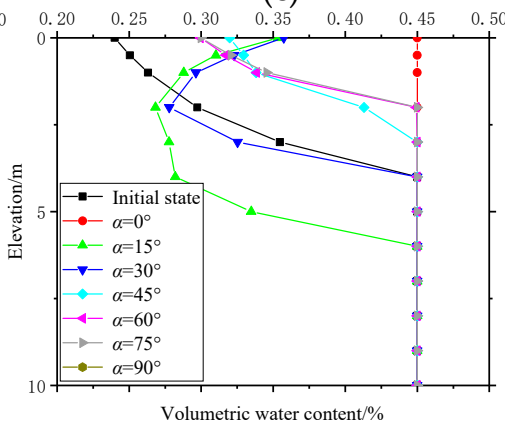

(f)

Figure 5. Variation of volumetric water content under different $\alpha$ values for sandy soil. (a) Top of the slope with $k_{r}=10$. (b) Middle of the slope with $k_{r}=10$. (c) Toe of the slope with $k_{r}=10$. (d) Top of the slope with $k_{r}=100$. (e) Middle of the slope with $k_{r}=100$. (f) Toe of the slope with $k_{r}=100$.

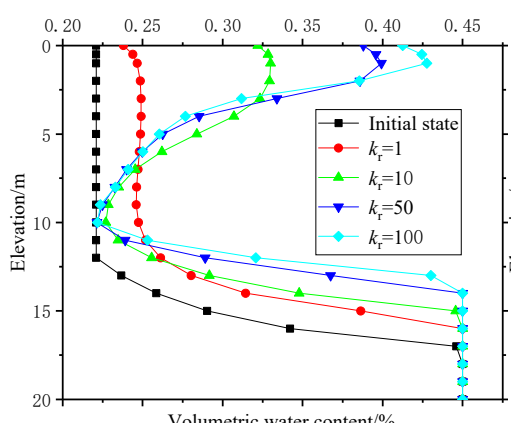

(a)

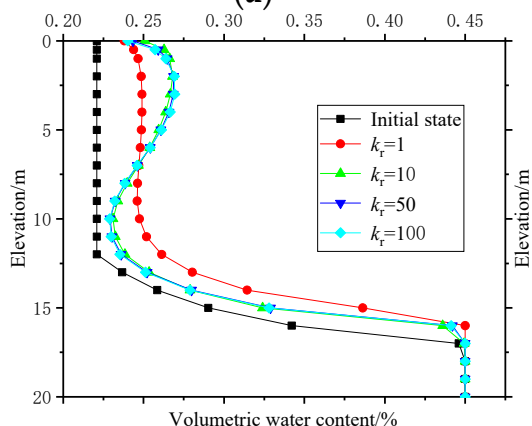

(d)

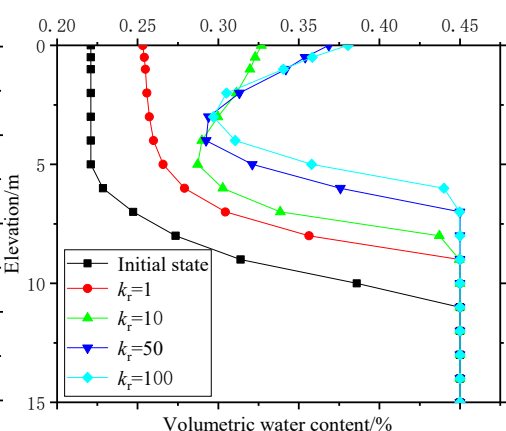

(b)

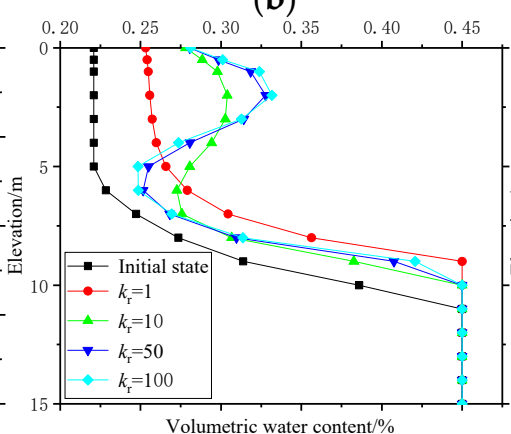

(e)

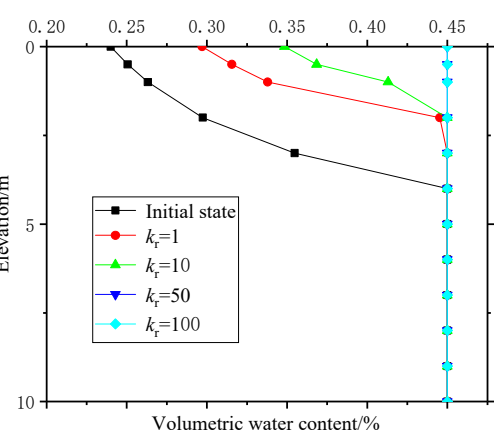

(c)

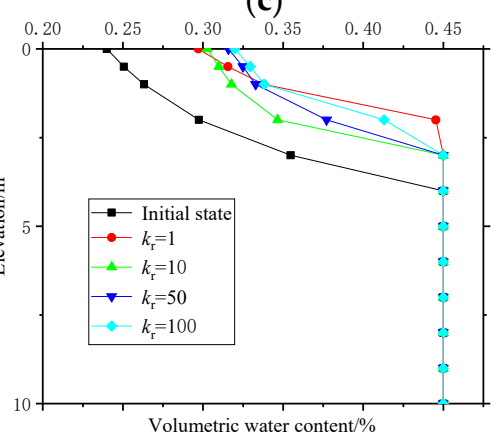

(f)

Figure 6. Cont. 


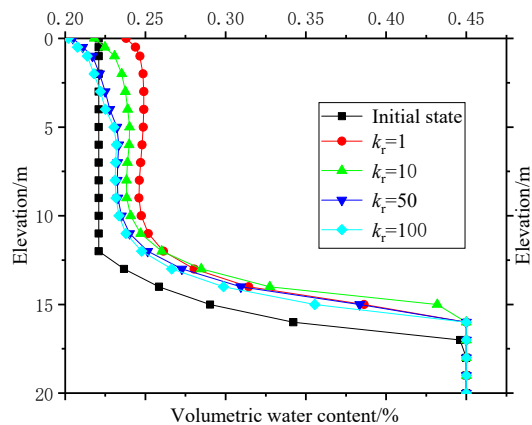

(g)

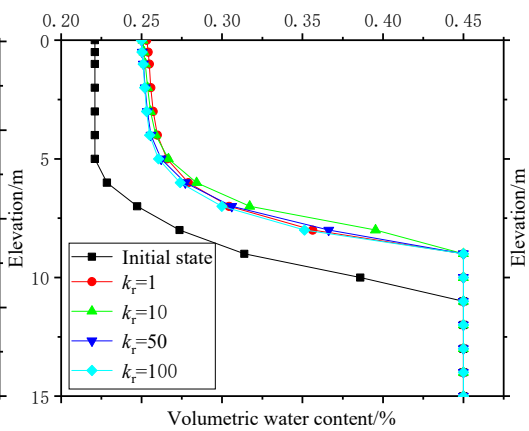

(h)

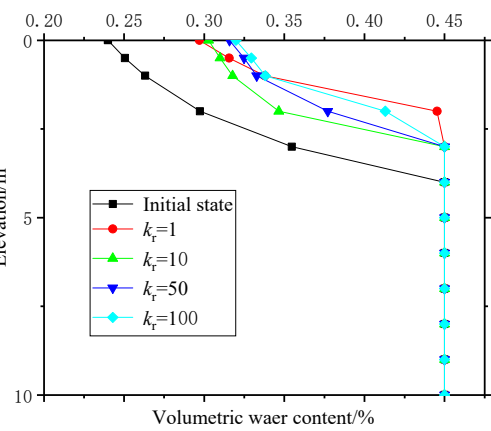

(i)

Figure 6. Variation of volumetric water content under different $k_{r}$ values for sandy soil. (a) Top of the slope with $\alpha=0^{\circ}$. (b) Middle of the slope with $\alpha=0^{\circ}$. (c) Toe of the slope with $\alpha=0^{\circ}$. (d) Top of the slope with $\alpha=45^{\circ}$. (e) Middle of the slope with $\alpha=45^{\circ}$. (f) Toe of the slope with $\alpha=45^{\circ}$. (g) Top of the slope with $\alpha=90^{\circ}$. (h) Middle of the slope with $\alpha=90^{\circ}$. (i) Toe of the slope with $\alpha=90^{\circ}$.

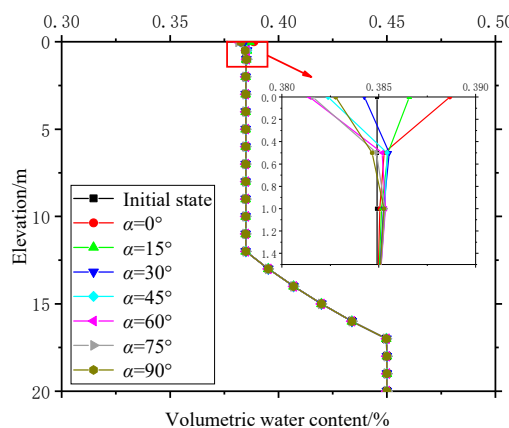

(a)

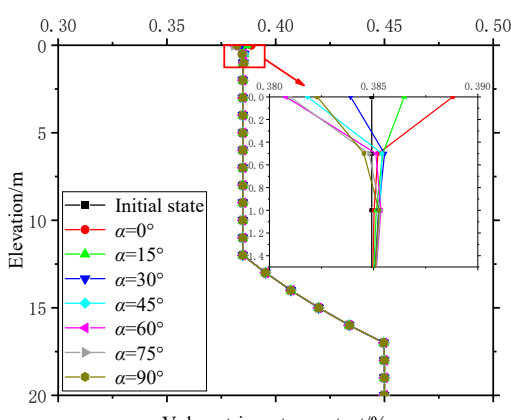

(d)

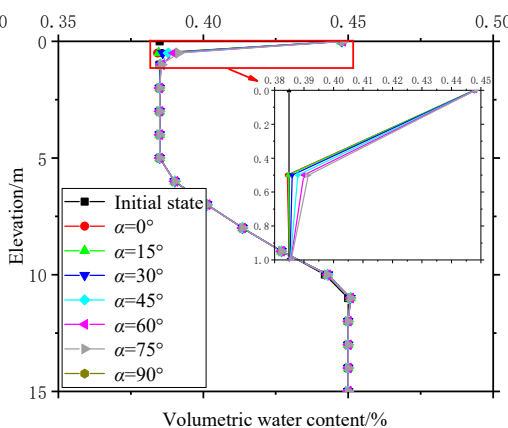

(b)

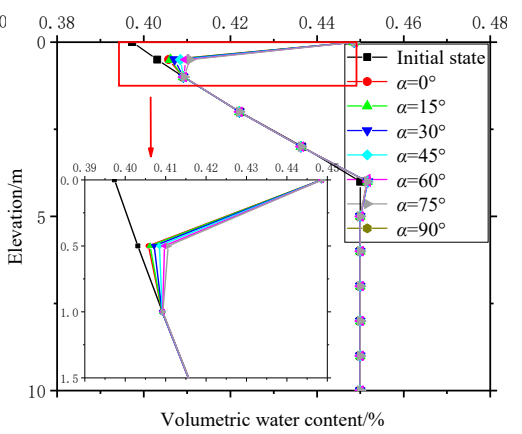

(c)

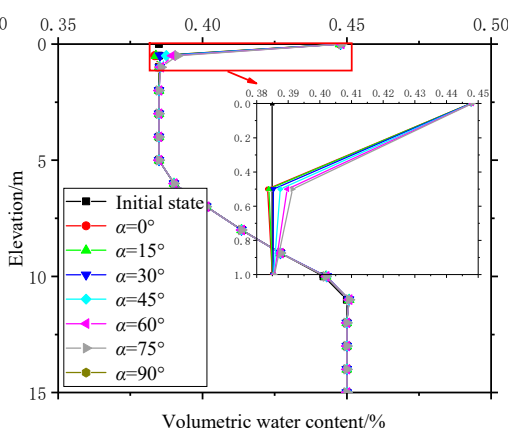

(e)

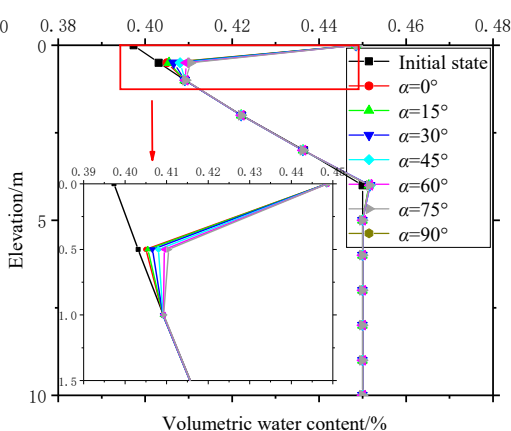

(f)

Figure 7. Variation of volumetric water content under different $\alpha$ values for clayey soil. (a) Top of the slope with $k_{r}=10$. (b) Middle of the slope with $k_{r}=10$. (c) Toe of the slope with $k_{r}=10$. (d) Top of the slope with $k_{r}=100$. (e) Middle of the slope with $k_{r}=100$. (f) Toe of the slope with $k_{r}=100$. 


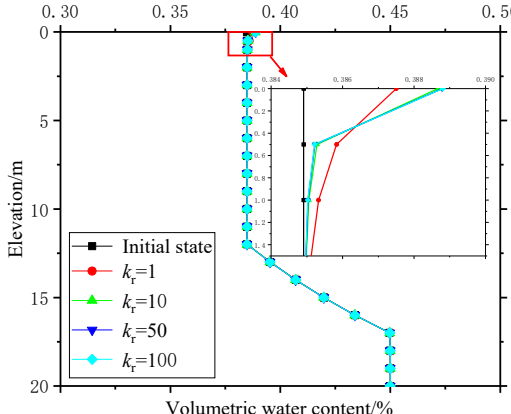

(a)

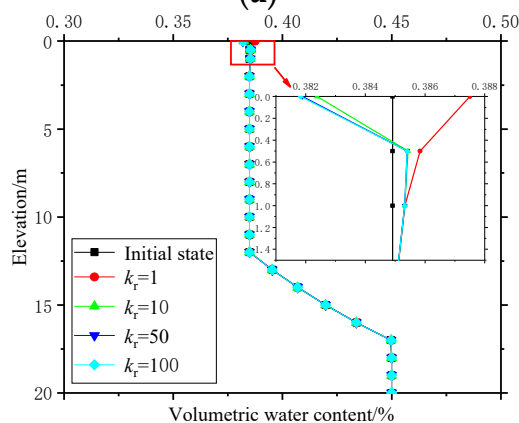

(d)

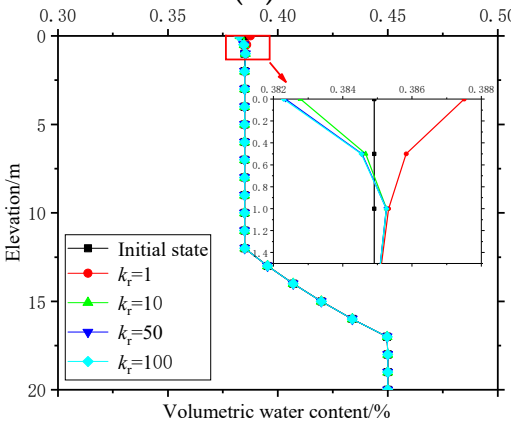

(g)

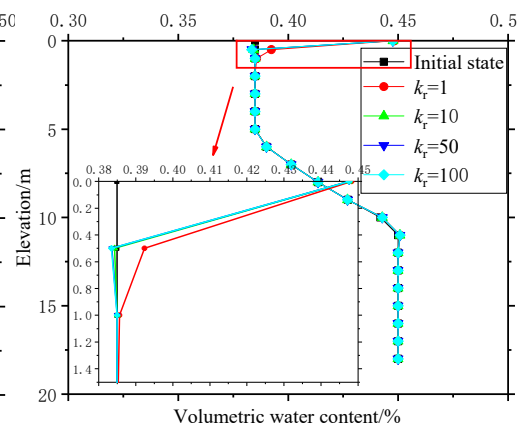

(b)

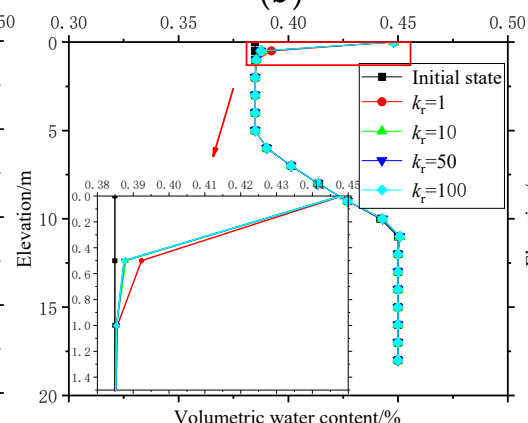

(e)

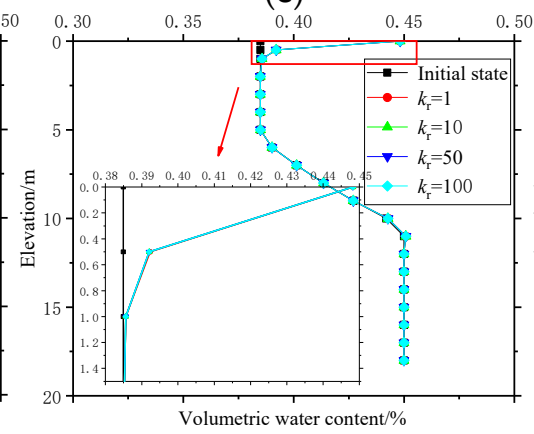

(h)

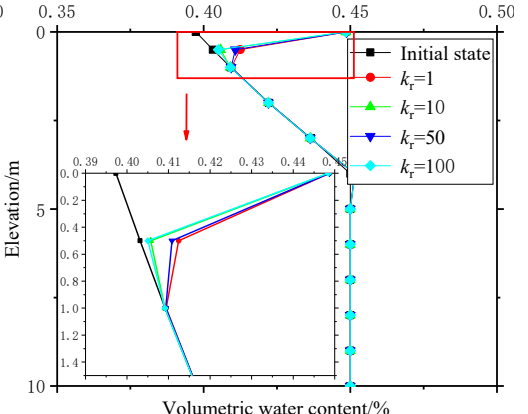

(c)

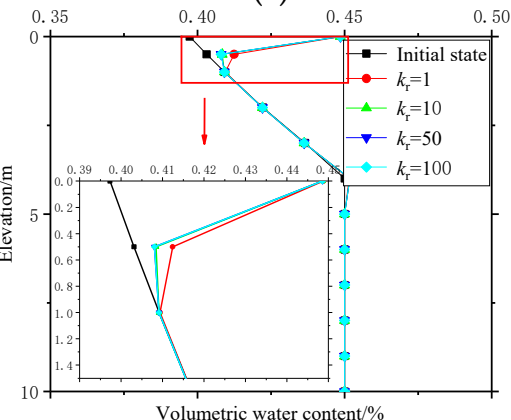

(f)

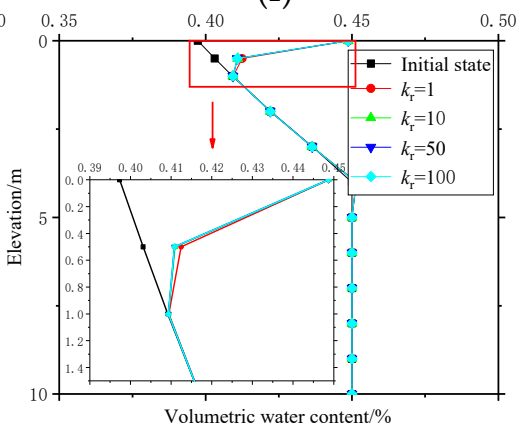

(i)

Figure 8. Variation of volumetric water content under different $k_{r}$ values for clayey soil. (a) Top of the slope with $\alpha=0^{\circ}$. (b) Middle of the slope with $\alpha=0^{\circ}$. (c) Toe of the slope with $\alpha=0^{\circ}$. (d) Top of the slope with $\alpha=45^{\circ}$. (e) Middle of the slope with $\alpha=45^{\circ}$. (f) Toe of the slope with $\alpha=45^{\circ}$. (g) Top of the slope with $\alpha=90^{\circ}$. (h) Middle of the slope with $\alpha=90^{\circ}$. (i) Toe of the slope with $\alpha=90^{\circ}$.

\subsubsection{Sandy Soil}

The variations of volumetric water content of sandy soil for different sections under different anisotropy direction $\alpha$ values are shown in Figure 5.

For the top of slope, the volumetric water content on the surface decreased with the increase of $\alpha$. This is because $k_{x}$ was greater than $k_{y}$. When $\alpha=0^{\circ}$, the vertical permeability reached the minimum, so the rainfall was hard to infiltrate, and the rain water accumulated in the shallow part of the slope. With the increase of $\alpha$, however, the vertical permeability increased, and the rain water was easier to infiltrate into the deep part, thus leading to the decrease of the surface volumetric water content. What should be noticed is that when the anisotropy ratio was small (i.e., $k_{r}=10$ ), the impact of rainfall on the volumetric water content was mainly reflected on the slope surface; but when the anisotropy ratio was larger (i.e., $k_{r}=100$ ), not only the slope surface but also the deep area were violently influenced, especially for $\alpha=0^{\circ}$ and $\alpha=15^{\circ}$.

For the middle of slope, the volumetric water content was affected by the combined effect of rainfall infiltration and the rainfall excretion from the slope top. The increase of $\alpha$ also decreased the 
volumetric water content on the surface as was illustrated in the previous paragraph. The combined effect, however, made the maximum surface volumetric water content happen at $\alpha=15^{\circ}$.

For the toe of slope, the variation of volumetric water content was similar to the slope top and middle In the condition of $\alpha=0^{\circ}$, however, the whole section did not reach saturation with $k_{r}=10$, but reached saturation with $k_{r}=100$.

Figure 6 shows the variation of volumetric water content under different $k_{r}$ values. For the top of slope, the volumetric water content under different $k_{r}$ values was greatly affected by the values of $\alpha$. When $\alpha$ was relatively small (i.e., $\alpha=0^{\circ}$ ), the surface volumetric water content increased with the increase of $k_{r}$. This is because the increase of $k_{r}$ decreased the horizontal permeability, thus leading to a higher surface volumetric water content. Meanwhile, rain water was easier to infiltrate through the horizontal direction when $k_{r}$ decreased, which rose the underground water level, thus leading to the increase of the deep volumetric water content. Yeh H.F. et al. (2018) [44] conducted relevant.simulations and the results were similar to current research results. However, the increase of $\alpha$ values made the difference of volumetric water content between different $k_{r}$ values smaller. This is because the vertical permeability decreased with the increase of $\alpha$, and the rain water drained away rather than infiltrated directly into the slope soil.

For the middle of slope, the variation range of volumetric water content was larger than that of the slope top, and under the combined effect, the value of volumetric water content was also larger than that of the slope top.

For the toe of the slope, due to its lower terrain, the height of the initial water table to the surface of the slope toe was smaller, and it was affected not only by rainfall but also by the rain water from the slope middle. So it had a smaller unsaturated area and a larger volumetric water content. What should be noticed is that the whole section reached saturation when $\alpha=0^{\circ}$ and $k_{r}=50$ and 100, and did not reach saturation in other conditions.

\subsubsection{Clayey Soil}

The variations of volumetric water content under different $\alpha$ values are shown in Figure 7, and the variation of volumetric water content under different $k_{r}$ values are shown in Figure 8.

As can be seen in Figures 7 and 8 , the differences between different $k_{r}$ and $\alpha$ values was relatively small for clayey soil. This is because the clayey soil had a relatively lower permeability, and the rainfall was difficult to infiltrate. Only the rainfall infiltration depth varied for different locations of the slope. The rainfall infiltration depth increased with the decrease of distance to the slope toe, and the deep volumetric water content almost did not change.

Figure 6 shows the variations of volumetric water content for sandy slope. The permeability coefficient was high, which resulted in the obvious change in the variation of volumetric water content, and, in fact, the bending reflected the accumulation of rain water on the shallow part of the slope. However, it was different in the clay slope, which is shown in Figure 8. The low permeability coefficient made the rain water difficult to infiltrate into the soil, and the no-ponding boundary allowed the excess water to move away from the boundary. So once the rainfall stopped, the slope surface did not have rainfall infiltration boundaries anymore, and the bending effect was not so obvious. We can see the bending effect in Figure 8b,d, which was located in the slope middle, but the slope top (Figure 8a,c) was regarded as unchanged.

\subsection{Analysis of Rainfall Infiltration Depth, Rising Height of Groundwater, and Maximum Water Content of the Surface}

As can be inferred from Section 4.2, the hydraulic conductivity anisotropy ratio $k_{r}$ and $\alpha$ have a great impact on the seepage characteristics of the slope. In order to evaluate this comprehensively, the rainfall infiltration depth (RID), rising height of groundwater (RHG), and the maximum water content of the surface (MWCS) were defined, as shown in Figure 9. Figure 9a shows distribution of volumetric water content during the rainfall process each day at the toe section of clayey slope. 
The surface volumetric water content gradually increased until the rain stopped. So the MWCS was defined to illustrate the saturation on the slope surface, which was the maximum surface water content when the rain stopped. During the rainfall, the wetting front developed into the deep area, and the RID is defined to characterize the influence of the rainfall on the slope deep, which was the height of the turning point to the slope surface. For sandy soil, as shown in Figure 9b, not only the surface volumetric water content but also the rising height of groundwater increased. So the RHG was defined to express the impact of rainfall on the sandy slope, which was the height of the turning point of the volumetric water content when the rain stopped to the turning point of the initial volumetric water content. What should be noticed is that there was no noticeable effect for the second to fifth rainfall day on the water content. This is because the hydraulic conductivity anisotropy was $k_{r}=10$ and $\alpha=0$. So for the sandy slope, rain water was hard to spread, and the difference was relatively small, as shown in Figure 10a. For clay soil, due to its low permeability, the difference seemed to be less obvious.

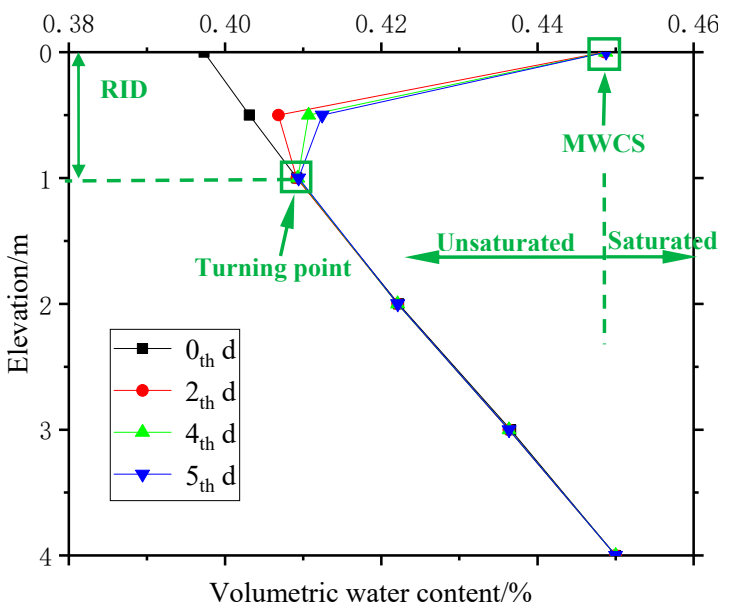

(a)

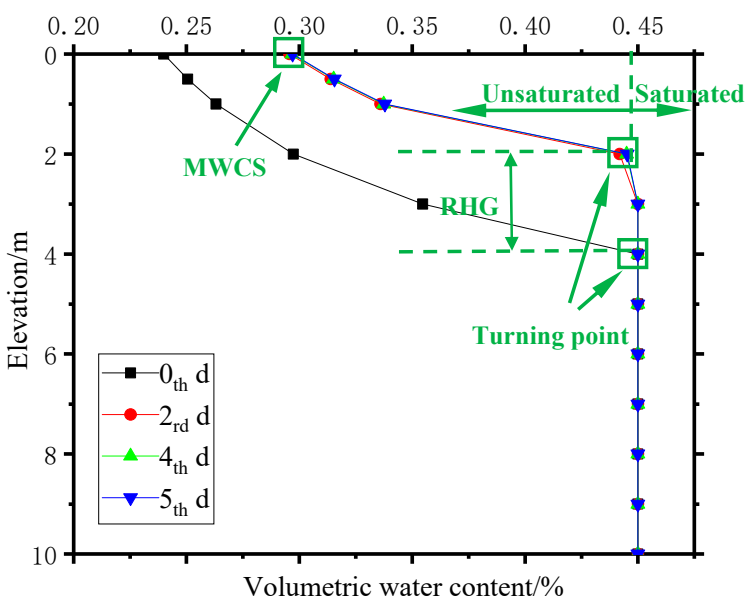

(b)

Figure 9. Variation of volumetric water content for sandy and clayey soil. (a) Sandy soil. (b) Clayey soil.

The MWCS for clayey and sandy soil slope is shown in Figure 10. For sandy soil slope, the MWCS increased to the maximum with the increase of $k_{r}$ and $\alpha$. When it came to the slope toe, the value of MWCS became larger than slope top and slope middle, which means that the slope toe was easier to reach saturation during rainfall. For clayey soil slope, the MWCS under different $k_{r}$ and $\alpha$ values was almost the same for the same section.

Figure 11 shows the variation of RID for clayey soil slope and the variation of RHG for sandy soil slope. For sandy soil slope, rainfall mainly caused the underground water level to rise, and the rising height was $-3-4 \mathrm{~m}$. What to be stressed is that when $k_{r}=100, \alpha=15^{\circ}$, the height of groundwater level decreased. We inferred this may be due to the fact that the vertical permeability coefficients were relatively small and the groundwater level was readjusted. For clayey soil slope, the variations of $k_{r}$ and $\alpha$ had little influence on the RID. For slope top, the RID was $0.5 \mathrm{~m}$, for slope middle it was $0.5-1 \mathrm{~m}$, and for slope toe it was $1 \mathrm{~m}$. 


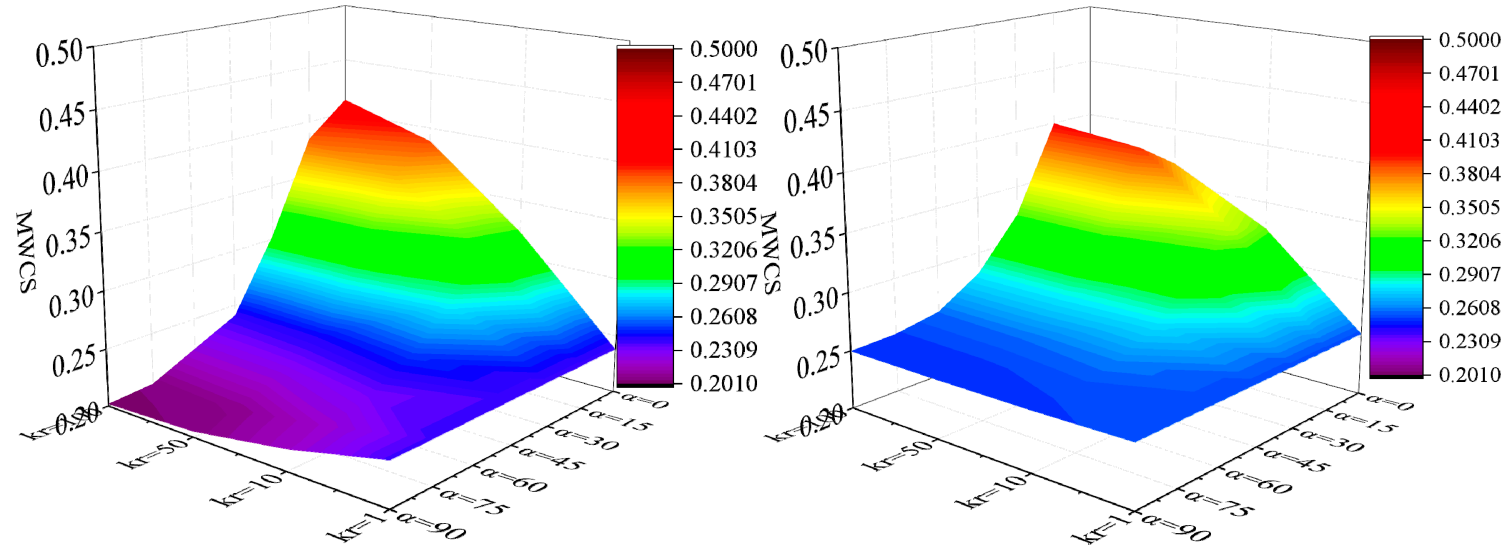

(a)

(b)

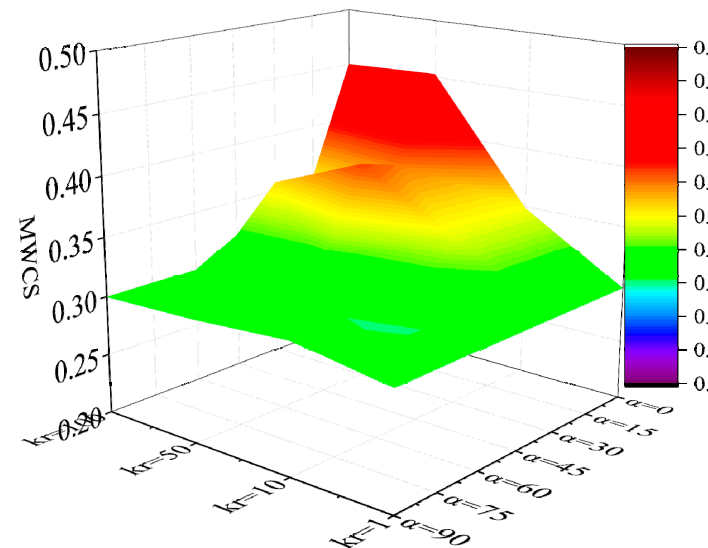

(c)

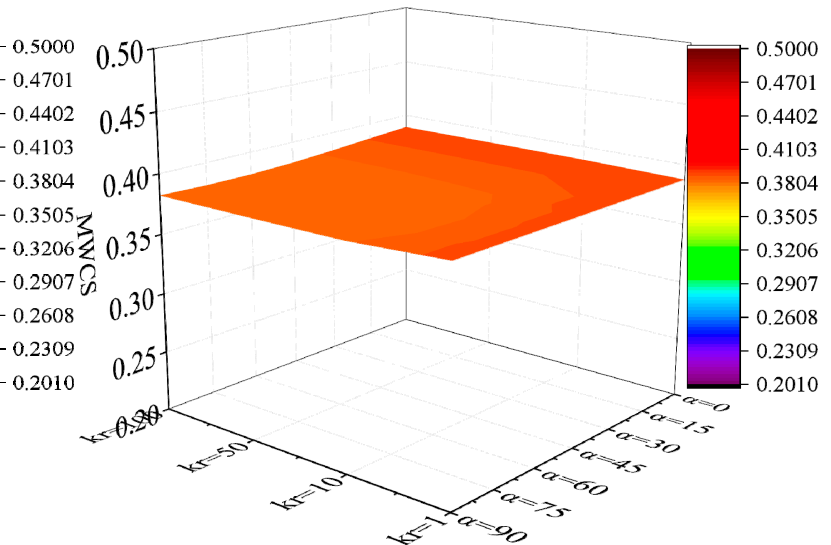

(d)

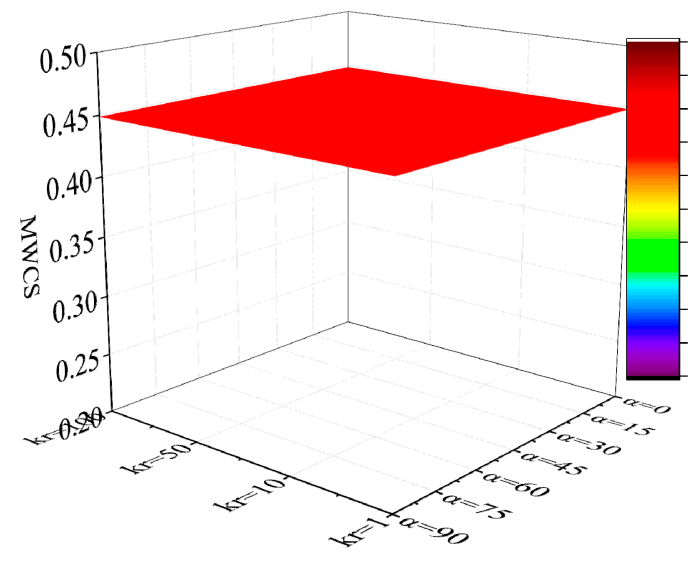

(e)

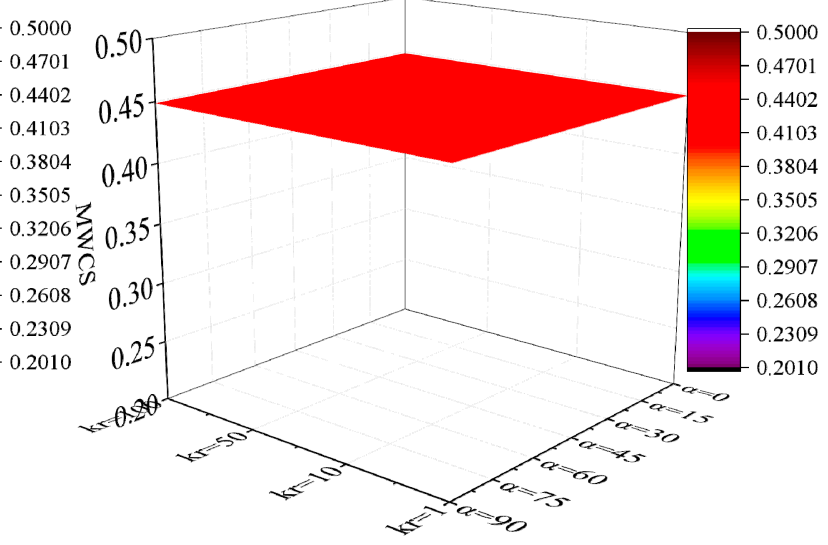

(f)

Figure 10. Variation of MWCS for clayey and sandy soil. (a) Top of the slope for sandy soil. (b) Middle of the slope for sandy soil. (c) Toe of the slope for sandy soil. (d) Top of the slope for clayey soil. (e) Middle of the slope for clayey soil. (f) Toe of the slope for clayey soil. 


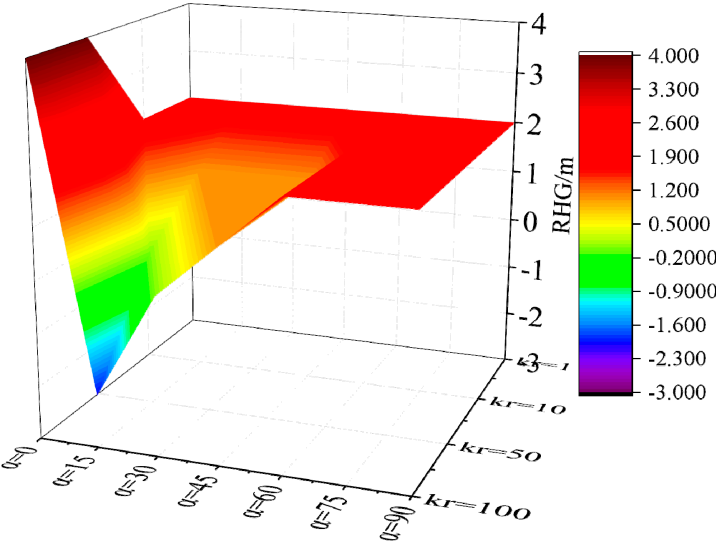

(a)

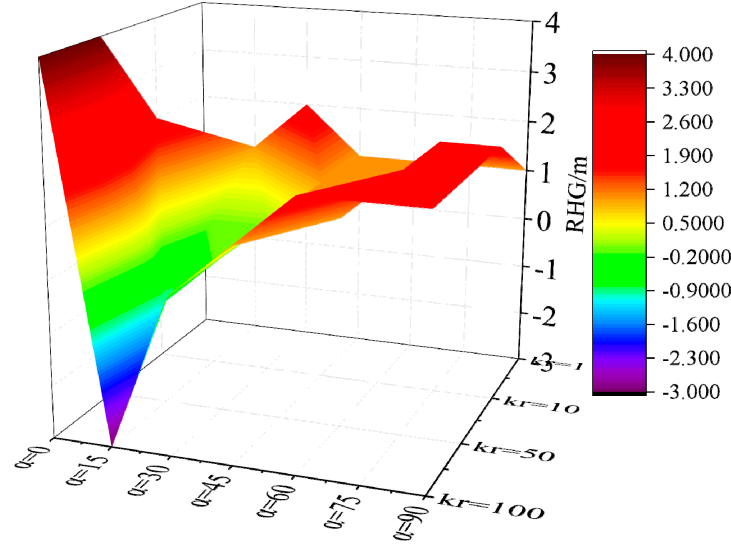

(c)

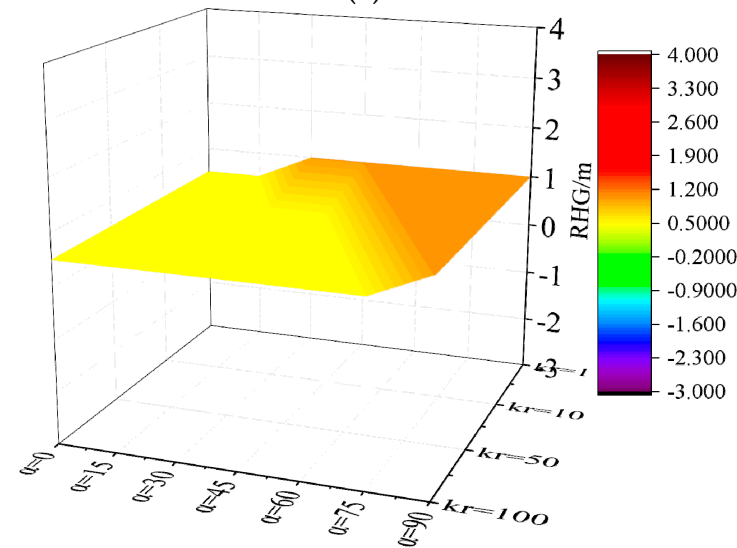

(e)

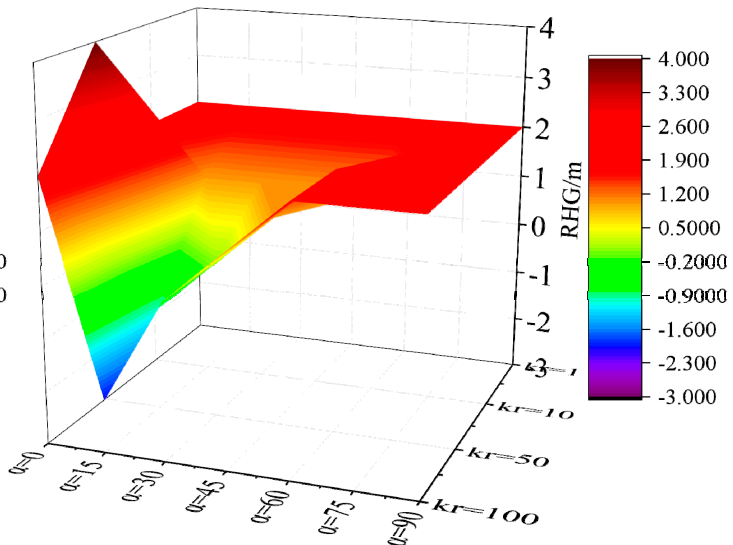

(b)

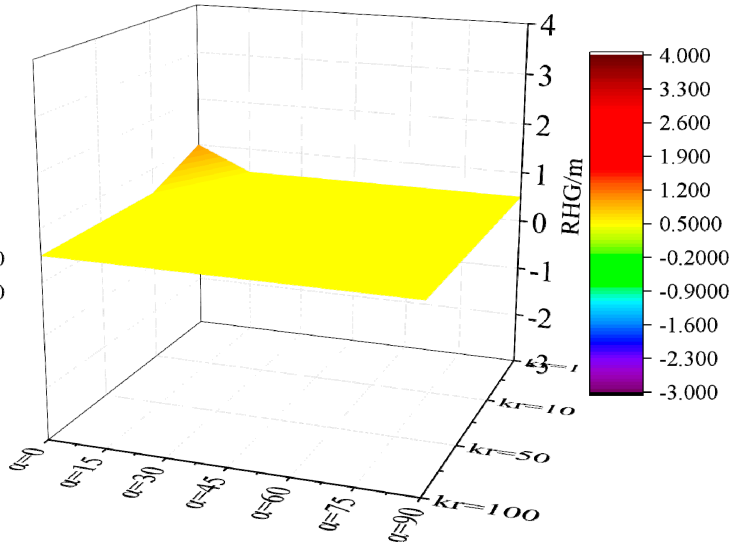

(d)

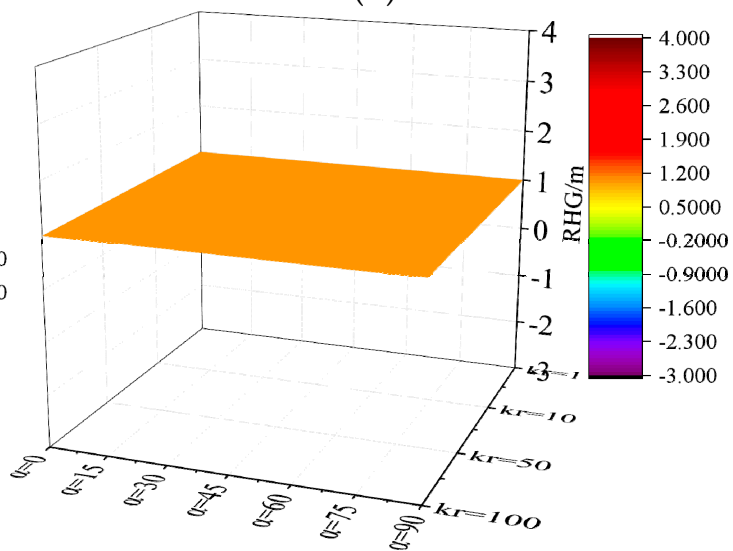

(f)

Figure 11. Variation of RID and RHG for clayey and sandy soil. (a) Top of the slope for sandy soil. (b) Middle of the slope for sandy soil. (c) Toe of the slope for sandy soil. (d) Top of the slope for clayey soil. (e) Middle of the slope for clayey soil. (f) Toe of the slope for clayey soil.

\subsection{Safety Factors}

The SLOPE/W module was utilized in this section to calculate the safety factors based on the Equation (5). In order to control the variables, the calculation parameters of soil strength were set according to Tang et al. [54], where $c^{\prime}=10 \mathrm{kPa}, \varphi^{\prime}=26^{\circ}$, and $\varphi_{b}=26$. The variations of safety factors (SF) under different $k_{r}$ and $\alpha$ values are shown in Figure 12. 


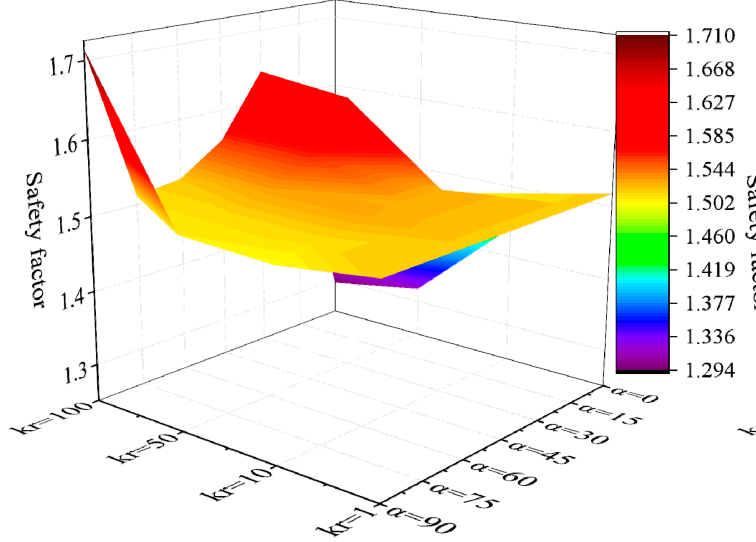

(a)

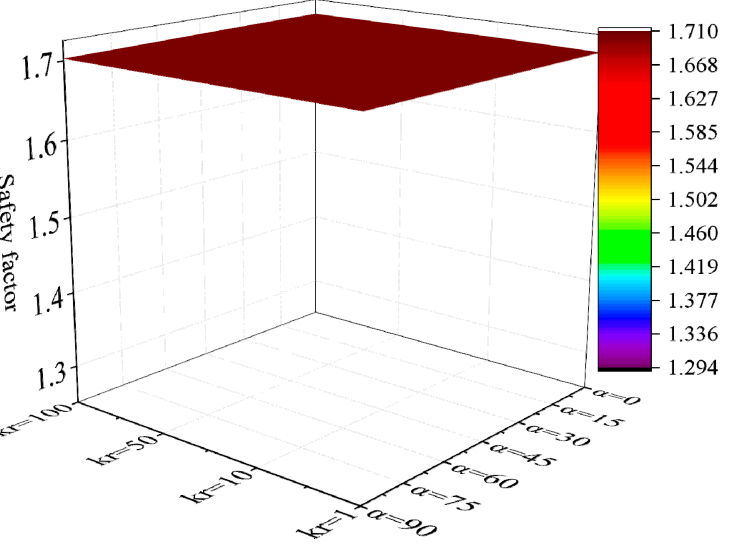

(b)

Figure 12. Variation of SF for clayey and sandy soil slope. (a) Sandy soil slope. (b) Clayey soil slope.

The variations of $k_{r}$ and $\alpha$ had a great impact on the SF for sandy soil slope. The minimum SF (1.3) happened when $k_{r}=100$ and $\alpha=0^{\circ}$. This is because in this condition $k_{x}>k_{y}$. The infiltration of rainfall in the horizontal direction led to a dramatic rise of the underground water, which led to the decrease of the soil strength and the SF. What was contrary was that when $k_{r}=100$ and $\alpha=90^{\circ}$, the SF reached the maximum (1.7), which was due to the low permeability coefficient in the horizontal direction $\left(10^{-6} \mathrm{~m} / \mathrm{s}\right)$, and the rainfall was difficult to infiltrate. It should be noticed that the SF increased when $k_{r}=100$ and $\alpha=15^{\circ}$, which was because, in this situation, the underground water level decreased and the soil strength increased.

For clayey soil slope, rain water was difficult to infiltrate into the soil due to its low permeability, and the SF remained 1.7 under different $k_{r}$ and $\alpha$ values, which was more stable than sandy soil slope under the same situations.

\section{Conclusions}

In this paper, the seepage characteristics and stability of slope in Luogang District, Guangzhou City, China were numerically simulated, considering the effect of sandy and clayey soil and the influence of the hydraulic conductivity anisotropy ratio $k_{r}$ and direction $\alpha$. The following conclusions can be obtained:

(1) The initial conditions are important for the subsequent calculation of unsaturated seepage. In this paper, the initial maximum suction of sand and clayey soil of $-45 \mathrm{kPa}$ was selected for numerical simulation, which was consistent with the actual situation.

(2) For sandy soil slope, the seepage characteristics and slope stability were greatly affected by the hydraulic conductivity anisotropy ratio $k_{r}$ and direction $\alpha$. The increase of $k_{r}$ promoted the rainfall infiltration, which made the groundwater level and the surface water content rise. The decrease of $\alpha$ prevented rainfall infiltration, which made the rainfall hard to infiltrate. For clayey soil, the variations of $k_{r}$ and $\alpha$ had little impact on the distribution of volumetric water content.

(3) The RID, RHG, and MWCS were defined to characterize the seepage response under rainfall. For sandy soil slope, the MWCS increased with the increase of $k_{r}$ and $\alpha$, and the RHG was $-3-4 \mathrm{~m}$. For clayey soil slope, the MWCS varied little and was higher than sandy soil slope, and the RID was $0.5-1 \mathrm{~m}$.

(4) The minimum SF happened when $k_{r}=100$ and $\alpha=0^{\circ}$, and varied dramatically with $k_{r}$ and $\alpha$ for sandy soil slope. The SF for sandy soil slope was 1.3-1.7, while the SF for clayey soil slope was higher than that of sandy soil slope, and remained about 1.7 .

(5) In actual engineering, it is necessary to consider the effect of the hydraulic conductivity anisotropy ratio $k_{r}$ and direction $\alpha$ for sandy soil slope. However, for clayey soil slope, it can be treated as isotropic medium without considering its anisotropy for the purpose of simplifying the calculation. 
Author Contributions: S.Y. completed the statistical analysis and wrote the paper; X.R., J.Z., and H.W. provided the writing ideas and supervised the study; Z.Z. did the numerical analysis. All authors have read and agreed to the published version of the manuscript.

Funding: This research was funded by The National Natural Science Fund (Grant No. U1765204).

Conflicts of Interest: The authors declare that there are no conflict of interest regarding the publication of this paper.

\section{References}

1. Luo, G.C.; He, Z.M.; Luo, X.; Hu, Q.G. Numerical Simulation of Slope Excavation in Highway Renovation and Expansion Project. Appl. Mech. Mater. 2014, 580, 827-830. [CrossRef]

2. Duong, T.T.; Do, D.M.; Yasuhara, K. Assessing the Effects of Rainfall Intensity and Hydraulic Conductivity on Riverbank Stability. Water 2019, 11, 741. [CrossRef]

3. Liu, C.; Hao, W.; Wang, J.; Bai, W.; Qin, Z.; Li, Z. Effect of Connectivity Rate of Dominant Joints Extending Outward of the Slope on High Slope Stability. J. Yangtze River Sci. Res. Inst. 2014, 31, 74-77.

4. Jotisankasa, A.; Mahannopkul, K.; Sawangsuriya, A. Slope Stability and Pore-Water Pressure Regime in Response to Rainfall: A Case Study of Granitic Fill Slope in Northern Thailand. Geotech. Eng. 2015, 46, 45-54.

5. Yufei, K. Infinite Slope Stability under Transient Rainfall Infiltration Conditions. Appl. Mech. Mater. 2014, 501, 395-398.

6. Oh, S.; Lu, N. Slope Stability Analysis under Unsaturated Conditions: Case Studies of Rainfall-induced Failure of Cut Slopes. Eng. Geol. 2014, 184, 96-103. [CrossRef]

7. Zhang, Y.; Zhu, S.; Zhang, W.; Liu, H. Analysis of deformation characteristics and stability mechanisms of typical landslide mass based on the field monitoring in the Three Gorges Reservoir, China. J. Earth Syst. Sci. 2019, 128, 9. [CrossRef]

8. Wu, L.; Wang, Z. Three Gorges Reservoir Water Level Fluctuation Influents on the Stability of the Slope's Analysis. Adv. Mater. Res. 2013, 739, 283-286. [CrossRef]

9. Zhang, M.; Dong, Y.; Sun, P. Impact of reservoir impoundment-caused groundwater level changes on regional slope stability: A case study in the Loess Plateau of Western China. Environ. Earth Sci. 2012, 66, 1715-1725. [CrossRef]

10. Chen, C.; Chen, H.; Wei, L.; Lin, G.; Iida, T.; Yamada, R. Evaluating the susceptibility of landslide landforms in Japan using slope stability analysis: A case study of the 2016 Kumamoto earthquake. Landslides 2017, 14, 1793-1801. [CrossRef]

11. Wensong, W.; Guangzhi, Y.; Zuoan, W.; Qiangui, Z.; Guansen, C.; Xiaofei, J. Study of the dynamic stability of tailings dam based on time-history analysis method. J. China Univ. Min. Technol. 2018, 47, 271-279.

12. Efremidis, G.; Avlonitis, M.; Konstantinidis, A.; Aifantis, E.C. A statistical study of precursor activity in earthquake-induced landslides. Comput. Geotech. 2017, 81, 137-142. [CrossRef]

13. Duggan, A.R.; McCabe, B.A.; Goggins, J.; Clifford, E. An embodied carbon and embodied energy appraisal of a section of Irish motorway constructed in peatlands. Constr. Build. Mater. 2015, 79, 402-419. [CrossRef]

14. Yu, S. Numerical Analysis of the Seepage Characteristics of Slopes with Weak Interlayers under Different Rainfall Levels. Appl. Ecol. Environ. Res. 2019, 17, 12465-12478. [CrossRef]

15. Pande, R.K.; Uniyal, A. The fury of nature in Uttaranchal: Uttarkashi landslide of the year 2003. Disaster Prev. Manag. 2007, 16, 562-575. [CrossRef]

16. Mo, P.-Q.; Yu, H.-S. Drained cavity expansion analysis with a unified state parameter model for clay and sand. Can. Geotech. J. 2017, 55, 1029-1040. [CrossRef]

17. Fernando, P.; Yipei, W.; Xu, L. Acid rock drainage passive remediation using alkaline clay: Hydro-geochemical study and impacts of vegetation and sand on remediation. Sci. Total Environ. 2018, 637, 1262-1278.

18. Amaral, L.F.; Vieira, C.M.F.; Delaqua, G.; Nicolite, M. Evaluation of Phyllite and Sand in the Heavy Clay Body Composition. Mater. Sci. Forum 2018, 912, 55-59. [CrossRef]

19. Tan, Z.; Cai, M. Multi-factor sensitivity analysis of shallow unsaturated clay slope stability. Int. J. Miner. Metall. Mater. 2005, 12, 193-202.

20. Qi, S.; Vanapalli, S.K. Influence of swelling behavior on the stability of an infinite unsaturated expansive soil slope. Comput. Geotech. 2016, 76, 154-169. [CrossRef] 
21. Loretta, B.; Carastoian, A. Slope Stability Analysis Using the Unsaturated Stress Analysis. Case Study. Procedia Eng. 2016, 143, 284-291.

22. Frank, G.; Martin, F.; Albert, B. Effects of vegetation on the angle of internal friction of a moraine. For. Snow Landsc. Res. 2009, 82, 61-77.

23. Wu, X.Z. Probabilistic slope stability analysis by a copula-based sampling method. Comput. Geosci. 2013, 17, 739-755. [CrossRef]

24. Zhang, Y.; Chen, G.; Wang, B.; Li, L. An analytical method to evaluate the effect of a turning corner on 3D slope stability. Comput. Geotech. 2013, 53, 40-45. [CrossRef]

25. Shi, Z.; Shen, D.; Peng, M.; Zhang, L.; Wang, F.; Zhene, X. Slope stability analysis by considering rainfall infiltration in multi-layered unsaturated soils. J. Hydraul. Eng. 2016, 47, 977-985.

26. Weizao, W.; Qiang, X.; Guang, Z. Centrifugal model tests on sliding failure of gentle debris slope under rainfall. Rock Soil Mech. 2016, 37, 87-95.

27. Liu, J.; Zhang, J.; Feng, J. Green-Ampt Model for Layered Soils with Nonuniform Initial Water Content under Unsteady Infiltration. Soil Sci. Soc. Am. J. 2008, 72, 1041-1047. [CrossRef]

28. Mein, R.G.; Larson, C.L. Modeling infiltration during a steady rain. Water Resour. Res 1973, 9, $384-394$. [CrossRef]

29. Chu, S.T. Infiltration during an unsteady rain. Water Resour. Res. 1978, 14, 461-466. [CrossRef]

30. Chen, L.; Young, M.H. Green-Ampt infiltration model for sloping surfaces. Water Resour. Res. 2006, 42, 887-896. [CrossRef]

31. Wu, C.P.; Luo, Y.S.; Chen, W. Indoor Model Experiment for Rainfall Effects on Bare Loess Slope Shape. Bull. Soil Water Conserv. 2013, 01, 121-125.

32. Li, L.; Luo, S.; Wang, Y.; Wei, W.; Li, C. Model tests for mechanical response of bedding rock slope UNDER different rainfall conditions. Chin. J. Rock Mech. Eng. 2014, 33, 755-762.

33. Zhang, Y. Study on Stability of Xiaokou Landslide under Different Rainfall Conditions. Ph.D. Thesis, SouthWest JiaoTong University, Chengdu, China, 2007.

34. Wang, H.; Chen, Z.X.; Zhang, D.M. Rock Slope Stability Analysis Based on FLAC3D Numerical Simulation. Appl. Mech. Mater. 2012, 170, 375-379.

35. Wang, X.; Li, Q.; Yu, Y. Simulation of the failure process of landslides based on extended finite element method. Rock Soil Mech. 2019, 40, 2435-2442.

36. Dou, H.; Han, T.; Gong, X. Reliability analysis of slope stability considering variability of soil saturated hydraulic conductivity under rainfall infiltration. Rock Soil Mech. 2016, 37, 1144-1152.

37. Song, Y.; Wu, Z.; Ye, G. Permeability and anisotropy of upper Shanghai clays. Rock Soil Mech. 2018, 39, 2139-2144.

38. Wang, T.; Yang, T.; Lu, J. Influence of dry density and freezing-thawing cycles on anisotropic permeability of loess. Rock Soil Mech. 2016, 37, 72-78.

39. Todd, D. Groundwater Hydrology; Jon Wiley \& Sons Inc.: New York, NY, USA, 1980.

40. Yuan, J.-P.; Lin, Y.-L.; Ding, P.; Han, C.-L. Influence of anisotropy induced by fissures on rainfall infiltration of slopes. Chin. J. Geotech. Eng. 2016, 38, 76-82.

41. Zhao, Y.; Wang, W.; Huang, Y. Coupling analysis of seepage-damage-fracture in fractured rock mass and engineering application. Chin. J. Geotech. Eng. 2010, 32, 24-32.

42. Mahmood, K.; Ryu, J.; Kim, J.M. Effect of anisotropic conductivity on suction and reliability index of unsaturated slope exposed to uniform antecedent rainfall. Landslides 2013, 10, 15-22. [CrossRef]

43. Dong, J.J.; Tu, C.H.; Lee, W.R. Effects of hydraulic conductivity/strength anisotropy on the stability of stratified, poorly cemented rock slopes. Comput. Geotech. 2012, 40, 147-159. [CrossRef]

44. Yeh, H.F.; Tsai, Y.J. Analyzing the Effect of Soil Hydraulic Conductivity Anisotropy on Slope Stability Using a Coupled Hydromechanical Framework. Water 2018, 10, 905. [CrossRef]

45. Yizhao, W.; Yaohua, S. Influence of Rainfall Infiltration on Slope Stability at Shallow Layer. J. Yangtze River Sci. Res. Inst. 2017, 34, 122-125.

46. Zefeng, J.; Dayong, Z. Critical slip field of slope with tension crack under intensive rainfall. Rock Soil Mech. 2016, 10, 25-34.

47. Al-Juboori, M.; Datta, B. Performance evaluation of a genetic algorithm-based linked simulation-optimization model for optimal hydraulic seepage-related design of concrete gravity dams. J. Appl. Water Eng. Res. 2019, 7, 173-197. [CrossRef] 
48. Al-Juboori, M.; Datta, B. Improved optimal design of concrete gravity dams founded on anisotropic soils utilizing simulation-optimization model and hybrid genetic algorithm. ISH J. Hydraul. Eng. 2019, 36, 1-18. [CrossRef]

49. Al-Juboori, M.; Datta, B. Reliability-based optimum design of hydraulic water retaining structure constructed on heterogeneous porous media: Utilizing stochastic ensemble surrogate model-based linked simulation optimization model. Life Cycle Reliab. Saf. Eng. 2019, 8, 65-84. [CrossRef]

50. GEO-SLOPE International Ltd. Seepage Modeling with SEEP/W 2007; Geo-Slope International Ltd.: Calgary, AB, Canada, 2010.

51. Fredlund, D.G.; Morgenstern, N.R.; Widger, R.A. The shear strength of unsaturated soils. Can. Geotech. J. 1978, 15, 313-321. [CrossRef]

52. Fredlund, D.G.; Rahardjo, H. Soil Mechanics for Unsaturated Soils; Wiley: New York, NY, USA, 1993.

53. Liu, J.; Zeng, L.; Fu, H. Variation law of rainfall infiltration depth and saturation zone of soil slope. J. Cent. South Univ. (Sci. Technol.) 2019, 50, 208-215.

54. Tang, D.; Li, D.; Zhou, C. Slope stability analysis considering antecedent rainfall process. Rock Soil Mech. 2013, 34, 3239-3248.

(C) 2020 by the authors. Licensee MDPI, Basel, Switzerland. This article is an open access article distributed under the terms and conditions of the Creative Commons Attribution (CC BY) license (http://creativecommons.org/licenses/by/4.0/). 